\title{
BLOQUEANDO ESTRADAS, CONSTRUINDO PONTES: AS MULHERES PIQUETEIRAS EM SALTA, ARgENTINA*
}

Andrea Andújar

Resumo:

Entre 1997 e 2001, Tartagal e General Mosconi, duas cidades desenvolvidas em função da exploração estatal de petróleo e localizadas na provincia de Salta, no noroeste da Argentina, foram cenário de conflitos sociais intensos. Dessas confrontações emergiu um novo ator social: o movimento piqueteiro. Tanto na construção do movimento quanto nos bloqueios de estradas, que era a principal forma de protesto, a presença ativa das mulheres foi fundamental. Este artigo analisa experiencias de mulheres na organização e liderança dos bloqueios de estradas, a través da interpretação de memórias elaboradas por elas durante entrevistas.

Palavras-chave: Mujeres piqueteras, historia social, Argentina.

Abstract:

Between 1997 and 2001, Tartagal and General Mosconi, two towns developed under the state petroleum exploitation and localized in the province of Salta, in the argentine northwest, were scenario of intense social conflicts. From those confrontations emerged a novel social actor: the piquetero movement. Both in the movement building and in the road blockades, which was the main way of protest, the active presence of women was fundamental. This article analyses women's experiences of participation, organization and leadership in the road blockades, by interpreting the memories they elaborated during interviews.

Key-words: "Piqueteras" women, social history, Argentina

\section{INTRODUÇÃO}

Maria nasceu há quase 65 anos em Santa Cruz de la Sierra, Bolívia. Mas há mais de 40 anos mora em General Mosconi, uma cidade na província de Salta, no noroeste da Argentina. Se algo pode defini-la, é o riso contagioso que se mistura com o relato de sua vida, cheia de casos e contradições políticas que a "tia Mari", como muitos a chamam carinhosamente na cidade, não se incomoda em demonstrar. Estudante universitária em seu país natal (chegou a cursar três anos de direito), Maria provém de uma família de proprietários rurais vinculados à exploração petroleira em Santa Cruz de la Sierra. Irmã mais velha de seis filhos e filhas que também estudaram na universidade, ela teve no passado uma ativa militância universitária que, como contava entre gargalhadas, realizava na "falange socialista de direita" de Sucre. Aos 22 anos, no entanto, aventurou-se por outros

\footnotetext{
* Tradução: Cristiana Schettini. Revisão da tradução: Fabiane Popinigis.

* Historiadora, Universidad de Buenos Aires. Pesquisadora do Instituto Interdisciplinario de Estudios de Género, Facultad de Filosofia y Letras. Correio eletrônico: andreaandujar@gmail.com
} 
caminhos, deixando de lado o futuro econômico promissor que seguramente a aguardava, preparado principalmente, pelos importantes contatos que sua família mantinha com um setor da classe dirigente boliviana. Foi assim que ela cruzou a fronteira com a Argentina. "Vim de passeio a Mosconi e fiquei", afirmava orgulhosa, enfatizando cada uma das palavras. Ali fez "boas amizades" e com uma delas, Dona Mafalda, ganhou uma licitação para explorar um salão de beleza que pertencia a Yacimentos Petrolíferos Fiscales (YPF), a outrora empresa estatal que explorava os recursos petroleiros da zona. Trabalhou no local durante três anos e, quando terminou o contrato, abriu seu próprio salão, "um cabeleireiro de bairro mais simplesinho", explicava. Durante muitos anos, Maria viveu comodamente. Mas em meados da década de 1990 a bonança acabou. Tinha muito poucos clientes e o negócio ia cada vez pior.

O panorama tinha começado a escurecer em 1992, quando a privatização da companhia petroleira deixou desempregada uma grande quantidade de trabalhadores, provocando um efeito devastador numa região que crescera ao calor da exploração estatal do ouro negro. As tentativas de fazer cooperativas ou de abrir pequenos comércios com o dinheiro obtido através das demissões voluntárias foram infrutíferas ${ }^{1}$. Encontrar um novo trabalho foi quase impossível. Era pouco o que se podia fazer frente à miséria que começava a imperar. Cansada das penúrias próprias e alheias, Maria decidiu, em maio de 1997, bloquear a estrada nacional 34 - que atravessa a cidade de General Mosconi e a vizinha Tartagal e as une com a fronteira com a Bolívia. Juntava-se, assim, a outras mulheres que, com seus maridos, filhos/as, irmãos/ãs, sublevaram-se frente ao destino de pobreza que as medidas neoliberais tinham selado, levantando barricadas para impedir a passagem de qualquer carro, pessoa ou mercadoria pela estrada até que algum funcionário do governo se apresentasse para escutar e responder suas reivindicações.

Este foi o primeiro de vários bloqueios de estradas que transformaram a província de Salta em palco de intensos conflitos sociais de ampla repercussão no futuro político regional e nacional. Em particular, os territórios de Tartagal e General Mosconi, localizados no norte

1 A demissão voluntária foi o eufemismo legal com que na Argentina se encobriram as demissões dos trabalhadores das empresas do Estado, entre outras. Consistia em que o/a trabalhador/a renunciasse à empresa em troca de uma soma de dinheiro pago como indenização. Para isso, ele/ela era pressionado/a com a ameaça de uma demissão posterior inevitável e sem essa soma. 
da província foram a arena na qual estes confrontos chegaram ao auge, dando lugar à emergência de um novo ator sócio-político: o movimento piqueteiro local.

Nestas ações beligerantes, o bloqueio de estradas, utilizado como ferramenta de protesto, foi simultaneamente a conseqüência e o caminho de formas comunitárias de organização e participação política contrárias ao modelo neoliberal, que atingiu a plenitude nas duas presidências consecutivas de Carlos Saúl Menem (1989-1999). De fato, foi durante aquela década que os setores dominantes da Argentina assentaram definitivamente as bases deste modelo cujos pilares foram a desregulamentação e a liberalização da economia acompanhada por uma ampla abertura comercial e financeira, a reforma laboral - centrada na flexibilização das condições e relações de trabalho - e a reestruturação do Estado, questão que incluía, entre outras coisas, o retiro das suas funções de proteção e seguridade social, concomitante à sua descentralização e a privatização das empresas públicas. Tudo isso havia sido delineado em planos anteriores, mas foi articulado de forma acabada no plano de conversibilidade posto em funcionamento por Domingo Caballo quando assumiu o ministério da Economia em 1991. Por um lado, o plano conduziu ao colapso do aparato produtivo industrial, já em estado crítico, e ao desmantelamento dos escassos vestígios do Estado de Bem-Estar. Por outro lado, provocou o aumento dos níveis de desemprego, pauperização e vulnerabilidade social a dimensões historicamente desconhecidas na Argentina.

A aplicação deste conjunto de reformas foi sustentada por um processo democrático que formulou acabadamente um discurso legitimador, restringindo a atividade política e a participação democrática da sociedade à eleição regular de representantes para o governo. Paralelamente, os setores dominantes pretenderam circunscrever a ação política legítima a um setor da elite que se apresentou como gerenciador dos recursos e assuntos públicos, e como delineador inquestionável de um programa econômico, político e social que prometia tirar a Argentina do subdesenvolvimento. Consequentemente, tentaram desativar tanto os protestos dos setores sociais prejudicados pela política neoliberal, como também as organizações que tradicionalmente os representavam (a Confederação Geral do Trabalho da República Argentina - CGTRA - ou as associações sindicais de primeiro grau, por exemplo), propalando uns e outras como ranços de uma sociedade caduca. Deste modo, os setores dominantes procuraram construir a política a partir da negação do político como ato social fundante e conflituoso, e como expressão da pluralidade de sujeitos que fazem parte da 
sociedade e dos múltiplos interesses que os atravessam². Assim, mercantilizaram-se amplas áreas da vida social, dispersando e atomizando formas, potenciais ou concretas, de protesto e resistência dos setores subalternos frente a avassaladora destruição do estado de bemestar.

No entanto, a partir de experiências de conflito social como as que se deram em Salta em 1997 e que em boa medida reeditavam aquelas ocorridas durante o ano prévio em cidades da Patagônia argentina ${ }^{3}$, as formas de protesto e confronto com o modelo econômico neoliberal e sua maneira de exercer a democracia, adquiriram uma contundência particular. De fato, a partir daquele momento, assistiu-se à abertura de uma etapa de ascensão da beligerância social, em que as modalidades e instrumentos do enfrentamento popular se articularam em torno dos bloqueios de estrada dinamizados pelos movimentos piqueteiros.

Tanto na construção destes movimentos, conformados fundamentalmente por pessoas desempregadas, como nos bloqueios de estradas, a presença ativa das mulheres foi nodal. Com experiências díspares de participação política prévia e com pertencimento de classe variado, estas mulheres não só teriam incitado o fustigamento das leis e normativas demarcatórias da ocupação dos espaços públicos na Argentina ${ }^{4}$, como também teriam impugnado as fronteiras do político e a circulação do poder. Também teriam desafiado seu

2 Esta negação do político assim definido é característica de todo estado capitalista. No entanto, com a globalização, adquire certas particularidades. Ver: Eduardo Grüner: "La tragedia, o el fundamento perdido de lo político". In: BORÓN, Atilio; DE VITA Alvaro, (compiladores).: Teoría y Filosofía política. La recuperación de los clásicos en el debate latinoamericano. CLACSO. Buenos Aires: 2002.

3 Durante o mês de junho de 1996, as e os habitantes das cidades de Cutral Có e Plaza Huincul na província de Neuquén protagonizaram um conflito de enorme envergadura, bloqueando as estradas provinciais e nacionais que atravessavam ambas as localidades. Por seis dias e seis noites, apesar das inclemências do crime, continuaram bloqueando as estradas exigindo que o governador aparecesse no lugar para responder frente a eles pela situação crítica que estavam vivendo a partir da privatização da YPF, alma também do desenvolvimento econômico e social da região. No ano seguinte e no mês de abril, um novo conflito paralisou a zona, iniciado por uma greve docente que terminou congregando toda a comunidade depois que um policial assassinou uma jovem, Teresa Rodriguez, que não estava participando do confronto. Um estudo dos dois conflitos pode ser visto em en Andrea Andújar "Pariendo resistencias: las mujeres piqueteras de Cutral Co y Plaza Huincul (1996)" In: BRAVO, María Celia, LOZANO, Fernanda Gil; PITA, Valeria (compiladoras): Historia de luchas, resistencias y representaciones. Mujeres en la Argentina, siglos XIX y XX. Editorial EDUNT, Tucumán: 2007.

4 Entre elas, pode-se citar o artigo 194 do Código Penal argentino que estipula que "o que, sem criar uma situação de perigo comum, impedir, estorvar ou entorpecer o normal funcionamento dos transportes por terra, água ou ar dos serviços públicos de comunicação, de provisão de água, de eletricidade ou de substâncias energéticas, será reprimido com prisão de três meses a dois anos". 
posicionamento na esfera da domesticidade, questionando os papéis de gênero socialmente instituídos.

Neste trabalho proponho abordar, então, a reconstrução das experiências das mulheres que participaram, organizaram e lideraram os bloqueios de estrada nas cidades de General Mosconi e Tartagal entre 1997 e 2001, recorrendo fundamentalmente à análise das memórias que, como processo de lembrança e reconfiguração dos significados das vivências do passado no presente, as mulheres construíram sobre suas próprias ações ${ }^{5}$. O marco temporal escolhido não é casual. Se 1997 marcou o ponto de inflexão deste tipo de confrontos na região, possibilitando que o emergente movimento piqueteiro começasse a assentar as bases de sua própria identidade ao canalizar múltiplos protestos, traçar alianças com diversos setores sociais e gestar formas alternativas de participação e ação, 2001 foi outro momento de inflexão, mas ao nível nacional. De fato, o aprofundamento das mobilizações sociais em diversos lugares do país contra as nefastas consequências da aplicação do modelo neoliberal, confluiu numa virulenta crise institucional em dezembro daquele ano que levou à renúncia de Fernando De La Rua à presidência da Argentina.

\section{EM BUSCA DAS PISTAS DAS MULHERES: A ORIGEM DAS PIQUETEIRAS}

As experiências de luta que deram origem ao movimento piqueteiro no norte saltenho estiveram ancoradas na destruição do chamado "mundo ypefeano", ou seja, de uma comunidade cujas relações sociais, políticas e econômicas foram moldadas sob o influxo e a presença da companhia petroleira estatal YPF'.

De fato, embora em suas origens, Tartagal e General Mosconi - fundadas em 1924 e 1927 respectivamente - tivessem como eixo das atividades econômicas a exploração

5 Os testemunhos que, como o de Maria, compõe o acervo central das fontes documentais deste trabalho, foram tomados pela autora nas localidades saltenhas (da província de Salta) que delimitam esta análise durante os anos 2003 e 2004.

6 É pertinente esclarecer que não existe um acordo geral em torno das origens da palavra "piqueteiro". Para alguns/algumas, a mesma retoma uma extensa tradição de luta do movimento operário argentino que remonta às organizações anarquistas e socialistas de fins do século XIX e começos do século XX, onde, em momentos de greves fabris, se faziam "piquetes" nas portas de entrada das fábricas para fazer propaganda do conflito ou evitar que entrassem os fura-greves. Para outros/as, o nome surge vinculado ao ato de bloquear o trânsito nas estradas de terra alternativas às estradas construídas pela YPF. 
florestal, sua constituição em aglomerados urbanos importantes deveu-se à exploração do ouro negro, descoberto na zona entre 1909 e 1911. No começo, a companhia norteamericana "Standard Oil Co." tomou a frente da produção. Mas em 1927, o General Enrique Mosconi, diretor da YPF - criada em 1922 - a impôs na exploração da jazida Acampamento Vespucio-Mosconi. Por volta de 1950, a retirada da empresa estadunidense de Tartagal permitiu à YPF a monopolização da produção petroleira nessa localidade.

A presença da YPF nestas zonas (cuja população chega a 80.000 habitantes) impulsionou o traçado urbano e habitacional, bem como a instalação e a provisão de serviços elétricos, gás, esgotos e hospitais, garantindo assim a socialização territorial e a expansão da atividade dos setores do comércio, da construção e dos serviços.

Por outro lado, a petroleira gestou nos trabalhadores e nas trabalhadoras um profundo senso de pertencimento e de identificação com ela, devido a várias questões. Em primeiro lugar, o elevado nível de vida propiciado pelos elevados salários, os benefícios de um bom plano de saúde e as férias pagas que a empresa provia. Isso dava origem, por sua vez, a um sentimento de orgulho e superioridade nas trabalhadoras e nos trabalhadores da YPF frente aos de outros setores produtivos, manifestado inclusive numa forma específica de se autodenominar: ser um "ypefeano/a" e não um/a trabalhador/a petroleiro/a, por exemplo.

Em segundo lugar, o/a "ypefeano/a" sabia que era parte de uma empresa estratégica para o desenvolvimento da economia argentina, ao mesmo tempo baluarte do discurso da soberania nacional e fundante do "estado de bem-estar" local. Isto aprofundava o sentimento de orgulho, mas também amortizava a percepção das contradições de classe presentes no interior do processo produtivo petroleiro, diluídas, desta forma, pelo fato da empresa ser propriedade do Estado. Assim, se trabalhar na YPF "era o melhor que podia te acontecer", como comentavam alguns dos ex- trabalhadores entrevistados, era a identidade conformada em torno a ser um operário ypefeano - engrenagem de uma "comunidade" na qual supostamente não existiam divisões entre exploradores e explorados -, a que se impunha sobre outras possíveis.

Para as mulheres (e em especial para aquelas que tinham filhas/os), a empresa petroleira estatal também deixava uma marca particular nas suas vidas ao assegurar a provisão daqueles serviços que resultavam ser fundamentais para seus interesses, 
constituídos a partir de seus atributos de gênero ${ }^{7}$, tais como escolas, centros esportivos ou jardins maternais. As vantagens de trabalhar na YPF podiam chegar inclusive a ser maiores. Yolanda, nascida em Tartagal, trabalhou como empregada administrativa na petroleira entre 1970 e 1993, ano em que foi obrigada a desvincular-se da empresa através da demissão voluntária. Quando sua filha menor, que naquele momento tinha 6 anos, foi diagnosticada com leucemia, a empresa responsabilizou-se não só por pagar o traslado de ambas a Buenos Aires (a $1.600 \mathrm{~km}$ de distância), mas também custeou o tratamento integral da menina enquanto continuou pagando o salário completo de Yolanda durante os 4 anos que ambas permaneceram em Buenos Aires. Neste sentido, as tarefas de cuidado e educação familiar encontravam-se amplamente facilitadas pela presença da petroleira estatal.

Mas com a privatização da empresa - entre 1991 e 1993 -, este "mundo ypefeano" caiu aos pedaços. A maioria dos/das trabalhadores/as foi despedida; as tentativas de montar cooperativas ou micro-empreendimentos com o investimento das indenizações terminaram sendo totalmente infrutíferas, escolas e hospitais fecharam suas portas para não mais abrilas. Por último, os níveis de desemprego e pauperização social se elevaram abruptamente. Assim, entre 1991 e 1997 a taxa de desemprego em General Mosconi aumentou exponencialmente, até afetar $65 \%$ dos seus 20.000 habitantes.

No entanto, a desestruturação do "mundo ypefeano" entranhou um impacto genericamente dissímil. Mulheres e homens não viveram este processo da mesma maneira e tampouco foram iguais as respostas que umas e outros articularam frente a ele.

Muitas das mulheres entrevistadas sustentaram que seus maridos se deprimiram, morreram, abandonaram suas famílias no meio de processos marcados por uma forte violência, ou se transformaram num estorvo dentro da casa. Enquanto que elas, segundo comentavam, “(...) tiveram que ficar mais fortes. (...) tiveram que ir ganhar o pão para elas e para seus filhos, porque ficaram elas como chefas de família, enquanto os maridos ficavam na casa (...)". Neste sentido, o final abrupto da "época dourada" ypefeana afetou tanto as condições materiais de existência como as subjetividades. E ambas instâncias foram vivenciadas de maneira díspar por mulheres e homens.

Para os ex-operários ypefeanos, a expulsão da máquina produtiva alterou profundamente não só sua situação econômica, como também sua posição de gênero como

7 MOLINEUX, Maxine: “Mobilization Without Emancipation? Women's Interests, The State, and Revolution in Nicaragua". In: Feminist Studies 11, № 2 (summer 1985), pp. 227-254. 
"provedores" da subsistência e reprodução familiar. Neste sentido, a impossibilidade de conseguir trabalho obrigou-os a passar muito mais tempo entre as paredes da casa, um espaço que, com base nas conotações sociais que o atravessam, torna-se singularmente complexo para a estadia prolongada de um homem. De fato, o que define um lugar não remete exclusivamente à localização física baseada num conjunto de coordenadas situadas num mapa que fixam um território preciso e limitado. Como sustenta Linda McDowell, “(....) os lugares se definem pelas relações sócio-espaciais que se entrecruzam neles, e proporcionam seu caráter distintivo $(\ldots)^{\prime \prime}$. Assim, por exemplo, o que distingue uma casa de uma fábrica não são só suas dimensões, sua arquitetura ou sua localização, e sim o que existe dentro. E isso está estipulado pelas práticas sociais que ali são levadas a cabo, as relações de poder que são artífices e ao mesmo tempo produtos destas práticas, e as marcas de inclusão/exclusão que determinam quem pertence a um lugar e quem fica fora, quem tem legitimidade para agir nele e quem não tem. Assim, os espaços não são fixos, embora definam limites e delimitem identidades. São fluidos e conflitivos, justamente porque apesar de aparentemente estanques, possuem diversos significados - que inclusive podem ser contraditórios - segundo as pessoas envolvidas neles. Além disso, representam hierarquias divergentes, sujeitas a conflitos e mudanças.

Dessa maneira, para uma mulher com filhos/as pequenos/as, esposa de um trabalhador assalariado, a casa pode adquirir conotações de refúgio e segurança, lugar de prazer e armazenamento de lembranças, mas também é o espaço que só ela está convocada a limpar e embelezar numa trabalhosa rotina diária sustentada por um trabalho invisibilizado, que a isola e que, inclusive, estigmatiza sua circulação por outros lugares (a rua, a estrada), plenos de outros significados. Para um homem, pelo contrário, a casa não é um espaço de trabalho, mas de descanso. Nele, apropria-se e beneficia-se do trabalho alheio - o da mulher - se bem que também pode ser um espaço de tensões no qual deva renegociar constantemente este "pacto" de apropriação unívoca.

Mas, quando para os homens deixa de ser um âmbito de repouso da jornada laboral, quando a falta de trabalho os obriga a ficar quase de forma permanente, num lugar carregado de uma marca desvalorizada por ser feminina, o sentimento que pode invadi-los é de inutilidade e vergonha. Isso é o que teria acontecido no caso daqueles que foram

8 MCDOWELL, Linda: Género, Identidad y Lugar. Valencia: Ediciones Cátedra, 2000, pág. 16. 
despedidos da YPF e que se viram impossibilitados de encontrar um novo posto de trabalho. Portanto, esta situação teria dado ensejo, como sustentam as e os entrevistados, a um tensionamento das relações familiares, primando as dissoluções dos vínculos matrimoniais em meio a um processo de enorme violência familiar, marcado pelo abandono das famílias pelos homens, a depressão, o alcoolismo e inclusive o suicídio.

Mas para as mulheres, embora traumática, esta situação não acarretava as mesmas opções. Em primeiro lugar, o condicionamento gerado pela maternidade e seus significados as impediu majoritariamente de abandonar seus filhos e filhas. Em segundo lugar, elas contavam com uma importante "autonomia" de decisão frente à "vontade" masculina no espaço doméstico, "autonomia" que tinha sido gerada e foi se acentuando a partir das características e a dinâmica particular do processo produtivo petroleiro. De fato, este último, fazia com que o ypefeano devesse permanecer fora de sua casa de 15 a 20 dias trabalhando nos campos de perfuração e extração, para voltar a casa por um escasso período de tempo. Isto forjou um tipo de vínculo com seu âmbito doméstico e as pessoas que o constituíam marcado pela ausência. Assim, lembra-se Estela, uma mulher adulta que chegou a General Mosconi com escassa idade. De fato, ela era ainda uma menina quando sua família decidiu deixar a Capital Federal e se instalar na localidade saltenha no começo da década de 1960. Seu pai tinha conseguido um posto de operário na YPF. Era escasso, portanto, o tempo que compartilhava com ela, seu irmão menor e sua mãe, já que o trabalho o obrigava a permanecer vários dias fora de sua casa. Então, nas lembranças de Estela sobre sua infância e adolescência, era sua mãe quem ocupava o centro da cena, administrando a economia caseira, subministrando cuidados e atenções, e supervisionando tudo aquilo que tinha a ver com as atividades e a educação de Estela e seu irmão. Ela narra inclusive que, para sua mãe, a presença do esposo durante os dois ou três dias de descanso que lhe correspondiam era vivida como uma interferência disruptiva no dia-a-dia. De acordo com suas lembranças:

\footnotetext{
“Meu pai ia por 15 dias e voltava 3, ia cada vez por mais dias. E às vezes era meio incômodo. Como ele tinha o barulho do poço nos tímpanos, quando chegava queria silêncio, dormia e dormia, e não queria que ninguém da família estivesse ali e isso alterava o nosso ritmo de vida. E nos primeiros dias, quando chegava, era insuportável. Minha mãe terminava se queixando e nós não víamos a hora de que ele fosse embora."
} 
Em termos similares refletia Maria Victoria, uma tucumana estabelecida em General Mosconi e casada muito cedo com um operário petroleiro, ao recordar que quando ele estava em casa "altera[va] o seu sistema, porque você define seus horários, sabe que está sozinha, organiza a vida, e quando eles chegam se interpõem com os tempos. Eu sentia que me amarrava." Em síntese, para muitas das mulheres que conviviam com os trabalhadores, estas prolongadas ausências masculinas permitiam o desenvolvimento de um importante grau de decisão no manejo de suas próprias vidas, e as de seus filhos e filhas, dispondo de uma maior margem de manobra para determinar o uso de seus tempos, de dinheiro, e da forma de se relacionar com o "fora" das paredes de sua casa. ${ }^{9}$

Um terceiro elemento para levar em conta remete ao pertencimento de classe destas mulheres. Embora, como disse anteriormente, tal pertencimento seja variado, majoritariamente elas são ou foram trabalhadoras estatais, empregadas domésticas, trabalhadoras por conta própria, donas de casa ou desempregadas. Em síntese: integrantes dos setores subalternos. Neste sentido, tal como sustenta Temma Kaplan, estas mulheres se constituem em garantidoras da coleta e distribuição dos recursos da comunidade de que formam parte, garantia que se torna mecanismo fundamental para preservar a vida e sobrevivência de sua comunidade. ${ }^{10}$ É a realização desta tarefa que teria enquadrado, na história pessoal e coletiva de muitas destas mulheres, a transcendência de sua atuação a partir do espaço doméstico para o espaço público.

Por último, muitas destas mulheres contavam com experiências de participação público/políticas prévias. Algumas tinham participado em bloqueios de pontes e estradas como forma de enfrentar a privatização da YPF, por volta de 1991. Outras lideraram bloqueios de estrada exigindo a provisão de serviços públicos básicos no mesmo período. Muitas chegaram inclusive a ocupar durante 23 dias, em 1996, a sede do Conselho Deliberante de General Mosconi (instituição legislativa local), exigindo a entrega de alimentos e subsídios para elas e seus filhos e filhas. Esta foi a experiência de Inês, uma

9 É pertinente esclarecer que quando falo da autonomia das mulheres em suas vidas e no cuidado de seus filhos/as, faço-o dentro de certos limites. A autonomia, neste caso, refere-se a certa independência do controle direto de seus maridos e não, como se poderia supor, a que elas estivessem em condições, pelo menos naquele momento, de desenvolver sua existência de acordo com seus interesses de gênero. Ver, para a formulação deste conceito e seu uso, MOLINEUX, op.cit.pp. 227-254.

10 KAPPLAN, Temma (1990): “Conciencia femenina y acción colectiva: El caso de Barcelona, 1910-1918”. In: AMALONG, J. y NASH, Mary, (compiladores): Historia y Género: Las mujeres en la Europa Moderna y Contemporánea. Valencia: Ed. Alfonso el Magnánimo, 1990. pp. 268 a 295. 
mulher desempregada, mãe de vários filhos e filhas e que participa de uma das organizações piqueteiras mais importantes da zona, a Unión de Trabajadores Desocupados (UTD). Segundo seu comentário:

\begin{abstract}
"Em 96 ocupamos o Conselho Deliberante de Mosconi durante 23 dias. A maioria éramos mulheres, e decidimos, todos os companheiros, tomar o Conselho Deliberativo porque no governo ninguém queria nos escutar. Dessa forma começamos, tínhamos o Conselho Deliberativo tomado e ali cozinhávamos, fazíamos pão caseiro porque tínhamos perto o quartel de bombeiros e eles traziam o forno e então fazíamos o pão. Gente de Buenos Aires mandava leite, mandava comida. O mais importante que precisávamos por causa das crianças. Não havia nada, havia muitas crianças desnutridas. (...) Aqui, em Mosconi, há muitas mães de muitos filhos. Há mães que têm sete, oito. Pelo menos eu sou uma que tenho, na minha são sete, perdi um menininho. Mas são mães de muitos filhos. E nós só pedíamos, basicamente, trabalho genuíno. E ali se comia, se dormia. Estávamos com as crianças ali. Para que íamos levá-los para casa se não tínhamos nada para dar a eles?"
\end{abstract}

Este testemunho permite entrever, em primeiro lugar, que o exercício da maternidade não só amparou as ações público/políticas de muitas destas mulheres, como também impregnou com seu significado os espaços em que elas levavam adiante tais ações. Assim, o Conselho Deliberativo, âmbito tradicionalmente dedicado a outro tipo de atividades vinculadas à administração dos assuntos comunitários, tornou-se o amplificador das demandas femininas. No mesmo sentido, o fato de que a intervenção pública delas estivesse mediada pela maternidade - o sofrimento causado pela fome dos/das filhos/as, neste caso, foi utilizado, como em tantas ocasiões na história, como razão legítima, e portanto tática, para enfrentar o Estado. Finalmente, este tipo de ação permitiu que elas ganhassem uma experiência de enfrentamento que depois voltaria a brotar na irrupção do bloqueio de maio de 1997. Em síntese, quando os efeitos devastadores da privatização da YPF colocaram em xeque a sobrevivência e o cuidado dos filhos e filhas - e com eles, da comunidade -, as mulheres articularam respostas em que as demandas e as capacidades de confrontação ganharam um protagonismo disruptivo e comovedor da ordem social vigente.

Foram estes fatores que se conjugaram na madrugada de 8 de maio de 1997 para que um grupo delas, acompanhadas às vezes por homens, jovens e adultos, outras resistindo à negativa de seus maridos e levando pela mão seus pequenos/as filhos/as, mobilizasse a sua comunidade em direção à estrada nacional no 34. Ali levantaram barricadas que sustentaram durante sete dias, impedindo o trânsito de qualquer veículo, mercadoria ou 
pessoa, exigindo a presença do governador Juan Carlos Romero - integrante do Partido Justicialista e aliado, nesse momento, do presidente Carlos Saul Menem -, a abertura de fontes de trabalho, o pagamento de salários atrasados aos trabalhadores públicos e a sanção de uma lei de fronteiras para criar uma zona franca para o intercâmbio comercial com a Bolívia. Jogaram assim as redes sobre as quais se construiria lentamente a Unión de Trabajadores Desocupados (UTD), a primeira e mais visível organização piqueteira da zona, que a teria como protagonistas e impulsoras, mas não como líderes.

Tentarei desentranhar, então, este aparente paradoxo.

\section{ALCANCES E LIMITES DA PARTICIPAÇÃO FEMININA}

Entre 1997 e 2001, a estrada nacional nํㅜ foi bloqueada em pelo menos cinco oportunidades. A média de duração de cada um desses bloqueios foi de aproximadamente uma semana. ${ }^{11}$

As atividades realizadas pelas mulheres durante o desenvolvimento dos bloqueios foram múltiplas: preparar o alimento, cuidar das barricadas e garantir a segurança dos piquetes, vigiando a eventual chegada de forças repressivas que, sob a ordem partida de juízes federais, poderiam tentar desalojar os bloqueios de estrada. Procuravam também impedir que o conflito pudesse ser manipulado por pessoas que obedecessem aos conflitos internos do partido provincial governante, o Partido Justicialista. Em todas essas atividades, misturavam-se ações vinculadas com a extensão amplificada à escala coletiva de seus papéis "naturais" de cuidadoras no espaço doméstico, com outras vinculadas à prática política/pública, que demonstraram uma leitura totalizadora e contra-hegemônica da realidade.

11 Frente a isto, os setores política e economicamente dominantes articularam respostas nas quais a criminalização do protesto transformou-se no denominador comum. E apesar de que em muitas circunstâncias viram-se obrigadas a empreender o caminho da negociação com os piqueteiros e as piqueteiras, quase sempre o fizeram depois de apelar para a máquina repressiva. Deste modo, o Estado argentino em Salta foi responsável pelo assassinato de cinco manifestantes, ocorridos durante os bloqueios de 2000 e 2001 em General Mosconi; da abertura de dezenas de causas penais contra ativistas de General Mosconi e Tartagal; de perseguições e prisões ilegais; do exercício da tortura contra presos e presas nos conflitos, e da virtual ocupação de General Mosconi por forças repressivas em várias oportunidades. 
Entre estas últimas, uma das mais importantes foi evitar as tentativas de manipulação política dos conflitos, tentativas vindas de disputas facciosas dentro do Partido Justicialista, que desde o retorno ao sistema democrático, em 1983, manteve de forma quase ininterrupta sua hegemonia no governo provincial. Assim, por exemplo, no bloqueio de 1997, um conhecido funcionário vinculado ao governador Romero, opositor ao governo municipal, quando se aproximou, foi cercado por um grupo de mulheres que exigiu, de forma ameaçadora, que ele se retirasse do lugar. Como comentou Mónica, proprietária de um pequeno armazém em General Mosconi e esposa de um ex ypefeano: "Se eles queriam estar ali, não tinha problema. Mas de nenhum modo como deputados, políticos desse ou daquele partido. Que venham como um simples cidadão a mais e acatem as decisões coletivas das assembléias."

Outra das medidas tomadas para garantir que o conflito e sua condução ficassem em mãos de seus próprios protagonistas radicou-se nas formas de organização e participação postas em prática. Nesse sentido, as decisões sobre aquilo que deveria ser feito para manter e fortalecer o protesto foram produto do exercício da democracia direta, através da participação nas assembléias realizadas em cada um dos piquetes. Depois de um debate em que as posições eram consensualizadas por aplauso, as mesmas eram expostas numa assembléia geral que determinava as linhas a seguir, as listas de condições e a eleição das pessoas que levariam adiante as negociações com as autoridades governamentais.

A presença feminina se evidenciou também no conteúdo das petições entregues aos funcionários governamentais, em que, além das reivindicações de postos de trabalho genuínos, créditos para as pequenas e médias empresas e auxílio-desemprego, predominavam as exigências de reinstalação de serviços públicos - como creches, subsídios para os refeitórios escolares e atenção sanitária, entre outras - ou isenção de pagamento dos referidos serviços para famílias de desempregados.

Pois bem: apesar desta elevada presença feminina na base do movimento piqueteiro e a importância de sua participação nos conflitos, foram escassas as mulheres que conseguiram ocupar postos de direção ou liderança nas organizações piqueteiras. Um exemplo disso pode se encontrar dentro da Unión de Trabajadores Desocupados (UTD).

Esta organização foi criada em abril de 1996, principalmente por ex ypefeanos que haviam participado em medidas de protesto contrárias à participação da YPF em 1991. Em 
geral, sua base estava composta por mulheres adultas desempregadas e por homens e mulheres jovens que nunca tiveram um trabalho estável.

Quando os ativistas da UTD mais reconhecidos descreviam a estrutura política da organização em diversos testemunhos, a horizontalidade era a característica que eles ressaltavam com mais frequência. E quando citavamos que ocupavam espaços de direção, era como referentes, e não como líderes. Aparentemente, a palavra "líder" tem um sentido negativo, já que remete à experiências de participação, organização política e formas de exercício do poder que a UTD rechaça. De fato, esta palavra, por exemplo, foi reiteradamente utilizada para designar o papel de condução em organizações de perfil genuinamente verticalista, tais como os sindicatos que nucleavam os trabalhadores petroleiros estatais - por exemplo o Sindicato Unido de Petroleros Estatales, SUPE -, onde a liderança foi combinada com um forte processo de burocratização, a consequente falta de democracia interna e a "traição aos interesses das bases". Nesse sentido, a escassa transparência nas decisões tomadas por este sindicato e, particularmente, o conhecimento de que as conivências de seu secretário geral com a direção menemista facilitaram o processo de privatização da YPF, foram mencionadas assiduamente pelos ex-ypefeanos da UTD como exemplo disso.

Portanto, entre as qualidades que sustentam a ocupação de um cargo de direção dentro da UTD, encontram-se a de "não se vender", ou seja, de não permitir ser cooptado pelo governo, e a coerência entre um discurso de confronto e uma prática beligerante, o que exige, sobretudo, "estar à frente das lutas", como me explicava Rosa, ou "enfrentar a situação", tal como sustentava María, ambas desempregadas e reconhecidas ativistas desta organização. No mesmo sentido, a destreza no conhecimento dos assuntos da organização e na administração dos projetos de trabalho elaborados pelos seus integrantes, bem como dos planos e subsídios governamentais, são condições fortemente valorizadas entre os e as ativistas. Além disso, as experiências sindicais de luta contra a privatização da YPF e, portanto, o fato de haver sido trabalhador da petroleira estatal, também pesam na hora de ocupar espaços de condução.

As mulheres realizam um sem-fim de tarefas dentro da UTD, muitas das quais são muito diferentes das que tradicionalmente são designadas a elas nos projetos elaborados 
mediante os subsídios de desemprego. ${ }^{12}$ Neste âmbito, os que comumente incluem as mulheres são as oficinas de costura comunitárias, hortas coletivas ou jardins maternoinfantis. Em Salta, ao contrário, embora não se neguem a realizar as tarefas mencionadas, elas também dirigem projetos de reflorestamento local, reciclagem de garrafas plásticas ou fabricação de tijolos. Portanto, a presença e as atividades assumidas por elas foram de suma importância tanto nos bloqueios de estrada como no fortalecimento da organização. Inclusive, na realização destas tarefas, as mulheres foram muito além das atividades especificamente designadas a elas, e empregaram saberes que serviram para criar laços solidários e afetivos dentro da organização, coadjuvando para fortalecer o compromisso de seus integrantes e seu crescimento. Um exemplo claro disso foi o sucedido com os "bocaseca", um grupo de jovens desempregados do bairro monense "Libertad", com os quais o relacionamento era difícil. De acordo com Rodolfo "Chiqui" Peralta, um ex-operário ypefeano que ocupa um cargo de direção na UTD:

\begin{abstract}
"os boca-seca, como Ihes chamam, eram famosos (...) Eram biscateiros de 18 a 20 anos que estavam na esquina, que insultavam quem passasse, batiam e o roubavam para beber, brigavam com gangues de outros bairros. Uh! Eram terríveis. E os trouxemos obrigados para cá porque tinham que trabalhar (...). Pouco a pouco foram se educando, sem que disséssemos muita coisa. Por isso acreditamos que o trabalho dignifica (...)".
\end{abstract}

Mais que o trabalho em si mesmo, quem teve muito a ver com a mudança desses jovens foi Dona Mari, a mulher a quem me referi no início deste artigo. Ela tinha sido posta a cargo do grupo por José "Pepino" Fernández, referência máxima da UTD. "Neste momento eu tinha 40 meninos, de 18 a 25 anos. Eram rebeldes! E quando os vi no primeiro dia, quase me fizeram chorar. Porque eram atrevidos, passava uma garota e diziam "que bunda!", "que tetas!", assim diziam. Jogavam pedras uns nos outros", afirmava ela sorridente. Como Dona Mari devia trabalhar com eles em tarefas de capinagem, encontrava-os cotidianamente durante a semana e, em suas próprias palavras, o que mais a preocupava era "como vou conquistar esses meninos". Foi assim que um dia, no final da jornada, Maria teve a idéia de convidá-los para que "depois do fim de semana cada um traga um pedacinho de alguma

12 É conveniente esclarecer que estes subsídios começaram a ser dados em meados da década de 1990 e que consistem de uma soma aproximada de $\$ 150$ pesos em troca de uma contraprestação de trabalho. Algumas vezes, eles foram a base de projetos articulados pelas organizações que os recebiam 
coisa e vamos cozinhar (...). Estávamos limpando a estrada. Quando nos sentamos para comer, ao meio dia, comecei a falar com eles. E um me diz: "por que discriminam a gente?" Porque vocês são muito atrevidos (...) porque vocês não têm noção, não têm respeito".

Foi assim, nos momentos de descanso e através das comidas que preparava para todo o grupo, que Maria foi ganhando a confiança deles. Suas conversas e atenções a converteram em conselheira e referência dos "boca-seca", como também no nexo entre eles e a UTD. Suas "conferências", como ela gostava de dizer, abarcavam muitos aspectos da vida destes jovens: o tratamento com as mulheres, o aprender a dividir o que se tinha, o respeitar-se mutuamente e o contribuir com dinheiro para a manutenção familiar eram temas que ocupavam várias vezes a cena. Como ela me contava: "E um dia estávamos conversando, e digo a eles, vocês têm que dar cinquenta pesos à mãe que dá o chá e a comida de todos os dias. E as mães ficavam todas contentes". Em outras ocasiões, frente a piadas sexistas e degradantes, Maria intervinha bastante incomodada: "Um dia disseram a um deles: "por que você está chegando tarde?". "Porque você veio e eu fiquei na cama com sua mulher. Tomei o leite e o vinho, tudo", respondeu-lhe. Então eu pensava em como ia pegá-los. Então disse: "Bruno, sexta feira vamos fazer um picadinho". E (quando nos sentamos para comer) comecei:

\footnotetext{
"Não quero mais ouvir vocês falando assim, porque se vocês têm suas mulheres, suas amantes, suas noivas, então vocês têm que respeitá-las porque são as mães de seus filhos, e vocês as escolheram, e tiveram filhos, porque as tem que fazer respeitar. O filho é dos dois, não quero mais uma brincadeira deste tipo, nunca mais".
}

Maria, conhecedora por sua vez dos níveis de violência doméstica existente em General Mosconi, agia para modificar os vínculos que eles estabeleciam em casa.

Por outro lado, a forma como ela coordenava e levava adiante essas tarefas coletivas, embora descansasse em certo modelo hierárquico que tentava sustentar por fora das relações "chefa-subordinados", mediante atitudes exemplificadoras, também incorporava elementos de participação ativa e igualitária. Segundo ela:

"Eu lhe dizia que porque eu os dirijo não é que sou seu chefe. Eu os controlo porque sou uma pessoa mais velha. Mas temos os mesmos salários, somos companheiros de trabalho, e nos devemos respeito um ao outro (...). E não é que eu os obrigue a trabalhar, eu chego com eles (....) conversamos um pouco e sem 
dizer nada pego minhas coisas e vou e cada um vai fazer seu ofício (...). E Ihes pergunto com as tarefas: vocês estão de acordo? Porque também têm direito a opinar, não posso ir e dizer... Assim não. Não é que eu vá e imponha".

Finalmente, tudo isto funcionou para modificar as pautas e as formas de sociabilidade dos "boca-seca", assim como suas relações com o resto da UTD. Maria atuou, então, amalgamando politicamente em sua prática, experiências provenientes de seus atributos de gênero. No que ela Ihes dizia, a forma e o cenário escolhido para fazê-lo, entrecruzavam-se visões da realidade, demonstrações de afeto e de apoio, ensinamentos através do exemplo, que davam conta de sua perícia para, a partir de uma subjetividade estritamente feminina e que não questionava necessariamente a relação entre os gêneros pela raiz, mover-se fluidamente entre o considerado próprio da vida privada e aquilo designado à vida pública. Isso Ihe permitiu, por um lado, impulsionar uma reflexão coletiva sobre o que estes jovens faziam num e noutro âmbito. E, por outro lado, ganhar para si mesma a visibilidade como referência da organização e de nexo entre eles e a UTD, ao mesmo tempo em que fortalecia e dava coesão a esta última.

No entanto, apesar de todas estas destrezas demonstradas pelas mulheres, a direção da UTD descansa majoritariamente nos ex-ypefeanos. Entre eles, a principal referência é José "Pepino" Fernández, que reúne muitas das características antes apontadas por Maria e Rosa para ocupar este papel. Quando os homens tentam explicar porque dentro da UTD a liderança recai majoritariamente sobre eles, as reflexões se centram tanto na composição de classe como na persistência de uma cultura "machista" vinculada a ela, e à própria aceitação das mulheres. Por exemplo, Rodolfo Peralta, outro ex-ypefeano dirigente da UTD, relatava o seguinte:

\footnotetext{
"Isto tem a ver com aquilo que está nutrido o movimento piqueteiro. Classe média não, mas de uma classe mais deprimida. E aí reina o machismo e a proeminência que tem o homem sobre a mulher. A mulher, mesmo nas camadas mais baixas da sociedade, aceita um segundo plano, acostumada. Não é porque não tenha capacidade, sozinhas ocupam um segundo lugar (...)".
}

Em outros casos, a reflexão se orienta mais à "vontade" das mulheres. De acordo com "Pepino" Fernández: "As mulheres não têm o mesmo papel que os homens. E as mulheres não fazem as reuniões para dirigir elas. Não querem pegar o compromisso, falar". 
Depois de defender que para que "as mulheres possam dirigir precisam primeiro organizarse entre si", Fernández deu exemplos de situações em que esta auto-organização era exitosa, levando em conta experiências vinculadas ao âmbito fabril. Referia-se, neste sentido, às trabalhadores têxteis da empresa Brukman Confecciones, localizada na cidade de Buenos Aires, que ocuparam e botaram para produzir a fábrica depois de seu abandono e fechamento decidido por seus antigos proprietários em dezembro de 2001.

Independente de que uma provável estratégia efetiva devesse consistir na criação de uma instância de participação própria para as mulheres reverterem a situação de "silêncio", subordinação ou falta de decisão autônoma, torna-se evidente também que, para ele, tal situação não é produto de uma relação desigual que implica tanto as mulheres como os homens e, portanto, a si mesmo; tampouco é casual que o modelo de mulher "independente" remeta às operárias que se destacam na ação pública/política. É verdade que a experiência das mulheres da fábrica têxtil é sumamente importante; mas também o é que muitas mulheres da UTD tenham protagonizado os bloqueios de estrada, enfrentado as repressões, planejado e organizado os projetos, fortalecido a organização e realizado numerosas ações que se parecem em muito às encaradas pelas mulheres da empresa têxtil. No entanto, as ações das mulheres da UTD não adquirem o mesmo valor para Fernández. Isso se deve, na minha opinião, tanto à experiência de participação prévia do próprio Fernández como ao horizonte no qual se inscrevem suas idéias sobre o modelo organizativo.

Nesse sentido, os antecedentes de participação e luta sindical dos homens devem ser postos também em questão na hora de analisar por que, no processo de cristalização da UTD como organização (por volta de 1999), as mulheres ficaram relegadas a um segundo plano hierárquico ou invisibilizadas para um líder como Fernández. Justamente, o peso de uma história marcada pelo pertencimento a uma empresa cuja mão-de-obra era majoritariamente masculina, bem como a experiência ganha no terreno da luta sindical no passado, colaboraram para que a direção da UTD se baseasse fundamentalmente nos exypefeanos e, dentro deles, nos que já haviam tido diversas ações relacionadas a uma prática sindical. Estes eram os casos de Peralta, que foi delegado sindical dos trabalhadores petroleiros de General Mosconi, ou de Fernãndez, que organizou vários conflitos trabalhistas quando trabalhava na YPF no sul argentino. Portanto, o modelo de referência organizativo básico foi o sindical que, pelo menos na sociedade argentina posterior aos governos peronistas de 1946-1955, esteve predominantemente conformado e liderado por homens. 
Assim, embora algumas mulheres ocupem posições intermediárias de direção e inclusive possuam uma forte ascendência em seus respectivos espaços de atuação política e social dentro da UTD, elas não são visibilizadas no mesmo nível que "Pepino" Fernández.

É interessante, nesse sentido, determo-nos na descrição e análise da experiência de Ica, em Coronel Cornejo, pequena localidade a $17 \mathrm{~km}$ ao sul de General Mosconi, que há décadas atrás foi uma importante zona de produção madeireira e cuja atividade atualmente está centrada na produção sojeira. Ica nasceu ali há 50 anos, e ali viveu sempre, caminhando por suas ruas sem asfalto, sulcadas por casas de madeira e sem água potável. Enquanto percorríamos o povoado, Ica entrelaçava sua biografia com a história do lugar e suas próprias ilusões. Assim,mostrava-me a estação de trem Belgrano, fechada quando se realizaram as privatizações dos trens em 1991, e que ela sonha em "restaurar e poder montar um enorme centro cultural. Porque se você olhar bem, ela é linda".

No entanto, não era essa sua única fantasia. Quando era pequena queria ser jornalista "porque o único que tínhamos era uma rádio. Mas eu só pude chegar ao primeiro ou segundo ano, e daí comecei a trabalhar... de empregada doméstica tanto em Vespúcio como em Mosconi". Criada junto com seus dois irmãos por sua mãe, Ica se casou aos 19 anos e, quando teve filhos, uma de suas aspirações maiores era que eles pudessem estudar e "levar uma vida em que não sofram como sofremos nós e que não tenham que passar tantas necessidades sem que ninguém os escute ou que os governos os convençam dando um saco". E Ica não estava disposta a abandonar seus sonhos, pelo menos não sem brigar.

Sua compleição física pequena e seu tom de voz baixo, no entanto, não permitem imaginá-la enfrentando um soldado que, batendo nela com uma moto, tentou tirá-la do bloqueio que ela mesma tinha iniciado sobre a rota 34, perto de sua casa, em maio de 1997. Ica não só ficou na estrada, como obrigou o soldado a se retirar envergonhado, dizendo: "Vocês estão aqui para cuidar da ordem e nossos filhinhos estão morrendo de sede". A ordem que Ica queria tampouco tinha a ver com a ordem segundo a qual ela era acusada de cometer um delito federal. A ordem para Ica era, por exemplo, obter água potável da que careciam os 2.700 habitantes de seu povoado e as fontes de trabalho que há tempos escasseavam por ali. Quando perguntei a essa mulher, desempregada, esposa de um extrabalhador madeireiro e avó de cinco meninos, se não tinha sentido medo, me respondeu frontalmente: "Como mulher, quando nos sentimos impotentes, não incapazes, mas impotentes, nos enchemos de coragem". Nesse sentido, o "nós" de Ica era uma referência 
identitária na qual ela diluía sua individualidade para fundir-se num sujeito coletivo estritamente feminino que, ancorado no exercício da maternidade e no cuidado dos outros, era capaz de irromper na cena pública interpelando o sentido de uma ordem que colocava em xeque suas vidas domésticas como mulheres e desempregadas, ao mesmo tempo que pretendia deixá-las inermes fora de casa.

Sua presença nas lutas, e sua capacidade de se colocar à frente delas, converteramna em um das pessoas mais reconhecidas pela sua comunidade. De fato, frente qualquer problema ou para propor medidas de luta e reivindicações às empresas ou aos poderes públicos locais, Ica é uma pessoa constantemente consultada, e seu papel em Coronel Cornejo também é sumamente reconhecido pelas referências da UTD de General Mosconi, que se referem a ela como "a dirigente" de Cornejo. Esta opção de compromisso público/político implicou para ela deixar de lado muito do que se referia à criação de seus filhos/as. Segundo narrou:

“(...) Eu como mulher acho que descuidei um pouco da minha família, mas acho que também é importante que eu faça alguma coisa pelos meus filhos. Então o pouco que eu posso fazer pelo bem da comunidade vou fazer e também estou fazendo por eles (...)."

De qualquer modo, Ica, apesar do reconhecimento múltiplo de que é objeto, evita identificar-se como uma líder, ou pelo menos, a utilizar isto como definidor de seu papel na UTD. Segundo ela “(....) pelo meu jeito discreto. Tenho um jeito discreto, talvez nunca saí com esse objetivo, eu acho que, com a atividade que se faça para a comunidade, se está demonstrando o amor que se tem pelas pessoas". Poderia se pensar que a oposição de Ica a se conceber como uma "líder" responde à mesma valorização negativa que esta palavra adquire também para outros referentes da UTD. Mas ela não rechaça a palavra, cujo uso, por outro lado, não objeta para "Pepino" Fernández, que considera como "o verdadeiro líder da UTD". Para seu caso, ela contrapõe duas idéias: a da liderança e a do amor pela comunidade. Argumenta então que se conforma em conseguir o segundo, à margem de se dedicar à construção da organização e à luta para melhorar as condições de vida de todos.

Muitas das mulheres argumentam exatamente o mesmo: que suas ações estão motivadas pelo amor, que é a recepção do afeto das outras pessoas que as fortalece, ou que suas pretensões políticas estão longe de aceder a algum tipo de direção. De fato, muitas das análises de suas próprias ações estão permanentemente atravessadas pelos laços afetivos. 
Mas não quando se referem aos homens. Nenhuma delas disse que o que motivava o compromisso de "Pepino" ou de Rodolfo Peralta se relacionava a alguma coisa assim. Pelo contrário, elas falavam de conviç̧ões, coragem para o enfrentamento, consistência entre atos e palavras, decisão de modificar o "status quo", conhecimento, experiência política, convencer-se a falar ou discutir nas assembléias, etc. Por exemplo, uma das mulheres que trabalha numa oficina de costuras comunitária em Coronel Cornejo me dizia: "Ica fez bem as coisas. Fez muito. Mas de repente tinha que estar com um homem porque um homem às vezes quer estar mais na frente".

Neste sentido então, o exercício da liderança remete a um espaço exclusivamente "masculino", já que todas as condições que a tornam possível se referem a atributos designados aos homens. E mais: quando as mulheres visivelmente carregam coragem, conviçção, experiência política, arrojo, etc., a proeminência que adquirem não necessariamente é suficiente, por um lado, para que se sintam em pé de igualdade com os líderes homens (ou para que o reconhecimento das mulheres restantes aponte nesta direção, em vez de preferir a presença de um homem); por outro lado, para reivindicar a liderança na organização, caso se compita por ela, ou se sentir legitimada ao se pensar como tal.

Além do mais, a dicotomia entre estar em casa, cuidando dos/as filhos/as, e estar na UTD, percorrendo os bairros, construindo a organização, relacionando-se com outras organizações, planificando ações, não é parte de uma tensão que se coloque para os próprios homens. Dessa maneira, as responsabilidades e as tarefas que a direção de uma organização demanda requerem tanto uma dedicação como um uso do tempo incompatível com as tarefas e com o uso do tempo dedicado em "cuidar dos outros". ${ }^{13}$

Finalmente, tornam-se difusos os limites entre a discriminação às mulheres no seio de uma organização e a auto-discriminação das próprias mulheres, originada - e não é demais dizê-lo - numa sujeição cultural apreendida desde o nascimento, que se reelabora, não sem resistências, de maneira permanente ao longo de todo o ciclo vital.

\footnotetext{
13 E quando uma mulher consegue inclinar a balança para o lado de se desligar das tarefas ligadas ao mundo doméstico, o que se costuma ativar, como no caso de Ica, é o sentimento de culpa.
} 


\section{REFLEXÕES FINAIS}

Apesar de as relações de gênero no movimento piqueteiro não expressarem uma dissolução das desigualdades entre homens e mulheres, não foi casual que a sua construção tenha sido o âmbito no qual muitas mulheres acharam um maior atrativo para seu envolvimento público/político. A horizontalidade na participação neste tipo de organização, as reuniões e assembleias quase permanentes e as práticas de uma democracia mais ligada à intervenção direta do que à representatividade foram elementos que geraram um marco de confiança e uma cotidianidade no trato e na criação de laços coletivos, possibilitando que as mulheres se animassem a falar, propor e debater as medidas a serem assumidas.

Por outro lado, nos bloqueios de estrada gestaram-se novas identidades que trocaram o ser desocupado pelo estar desempregado e ser piqueteiro/a. Nessa direção, autodenominar-se piqueteiro/a começou a remeter a uma noção de resistência frente à ordem vigente, questionando a degradação que submetia milhares de pessoas e exigindo respeito à dignidade própria. Dali então, se o conceito de desempregado/a implica estar fora das relações de produção, mas também que não se é nada fora delas, o conceito de piqueteiro/a reforça o reconhecimento de que por fora delas pode-se lutar, porque continua-se sendo, e torna a resignação, a angústia ou o desespero individual em capacidade beligerante coletiva. Em tal sentido, as mulheres puderam ganhar visibilidade própria ou se fazer escutar utilizando, a seu favor, na ação pública, os recursos que, até este momento, tinham-nas subsumidas na esfera da domesticidade.

No entanto, isso não permitiu dar continuidade à sua agência pública em termos de liderança dentro dos movimentos piqueteiros, pelo menos até a atualidade. Ou seja: a presença e auge dos mesmos em todo o país, não redundou ainda num maior afiançamento das mulheres em posições de direção. De fato, apesar delas constituírem entre $60 \%$ e $70 \%$ de tais movimentos ao nível nacional, os cargos de chefatura recaem quase exclusivamente nos homens. Frente a esta evidência, poderia-se dizer que a institucionalização dos movimentos piqueteiros como ator social e interlocutor reconhecido pelo estado, partidos políticos e, inclusive, algumas organizações ou centrais sindicais trouxe aparelhada a marginalização das mulheres nos espaços de tomada de decisão.

A explicação deste fato requer aprofundar a investigação histórica sobre este tipo de movimento. No entanto, e a título de hipótese, considero que as razões que dão conta desta 
marginalização não podem ser circunscritas ao âmbito da vontade individual das mulheres que fazem parte dos movimentos piqueteiros. A possibilidade de ocupar funções de liderança não decorre necessariamente do desejo de fazê-lo, mas das condições sociais que permitem às pessoas aplicar níveis de ativismo e participação social sustentados no tempo e que requerem tanto visibilidade própria como o reconhecimento dos/as outros/as. Dentro destas condições sociais, as tarefas assumidas pelas mulheres de acordo com a designação de papéis de gênero, embora possam potencializar sua participação pública em certas ocasiões, como demonstro neste trabalho, também obstruem a continuidade desta participação.

Mas ao mesmo tempo me pergunto até que ponto a marginação dos espaços de chefatura não é o resultado, também, do confronto de duas lógicas e formas diferentes de fazer política por homens e mulheres, e que transpassam seu pertencimento de classe. Nesse sentido, o tipo de racionalidade política e verticalização que acompanham o processo de institucionalização dos movimentos piqueteiros pode resultar em elemento expulsivo para as mulheres ou escassamente atrativo para elas. De fato, a liderança, embora receba diversas denominações e se apresente com conotações neutras, resume características que, a partir de uma perspectiva de gênero, se inscrevem nas normas pautadas para o comportamento masculino: dureza de caráter, firmeza no uso da palavra, segurança amparada pela razão para a expressão das idéias, coragem, etc. De tal modo que, aceder a isso significaria, para as mulheres, "masculinizar-se" ou obturar aqueles componentes de sua subjetividade que se encontram socialmente desvalorizados. Portanto, é factível que, nestes termos, o exercício da liderança não responda nem aos interesses nem às necessidades das mulheres tratadas neste trabalho. É possível, inclusive, que ao falar de piqueteiros e piqueteiras não nos refiramos sequer ao mesmo tipo de ator social, já que as experiências de mobilização, participação e organização de uns e outras não são idênticas entre si, da mesma maneira que se pode afirmar que a experiência de classe não é igual para homens e mulheres. 